\title{
A device-specific prioritization strategy based on the potential for harm to human health in informal WEEE recycling
}

\author{
Alessandra Cesaro ${ }^{1}$ - Vincenzo Belgiorno ${ }^{1} \cdot$ Mentore Vaccari $^{2} \cdot$ Aleksander Jandric $^{3}$. \\ Tran Duc Chung ${ }^{3} \cdot$ Maria Isabel Dias $^{4}$ - Andrew Hursthouse ${ }^{5} \cdot$ Stefan Salhofer $^{3}$
}

Received: 21 June 2017 / Accepted: 2 October 2017 /Published online: 20 October 2017

(C) The Author(s) 2017. This article is an open access publication

\begin{abstract}
In developing countries, the recovery of valuable materials from Waste Electrical and Electronic Equipment (WEEE) is carried out via uncontrolled practices, posing potentially severe risks both to human health and the environment. The assessment of the risk, which depends on both the kind and hazardous properties of the substances contained in WEEE, is currently limited as the exposure scenario for the single informal practice cannot be fully characterized for this purpose. In this context, this work proposes and evaluates a strategy to identify the relative potential harm of different kinds of WEEE by their content in metals, selected as the target substances of concern. This was based on the individual metal content, primarily located in the printed circuit boards (PCBs) of the different devices. The metal composition of the individual PCBs was identified and the dominant unregulated metal recovery practices were reviewed to identify the most suitable parameter to express the toxicity of these metals. Based on a mass-normalized cumulative toxicity, via the inhalation route, individual components were assessed from
\end{abstract}

Responsible editor: Philippe Garrigues

Alessandra Cesaro

acesaro@unisa.it

1 Sanitary Environmental Engineering Division (SEED), Department of Civil Engineering, University of Salerno, Via Giovanni Paolo II, 84084 Fisciano, SA, Italy

2 University of Brescia, Via Branze 43, 25123 Brescia, Italy

3 Waste Management Institute, BOKU University, Muthgasse 107, 1190 Vienna, Austria

4 Instituto Superior Tecnico, Campus Tecnologico e Nuclear, Universidade de Lisboa, Estrada Nacional 10, Bobadela, 2695-066 Loures, Portugal

5 University of West Scotland, Paisley Campus, Paisley PA1 2BE, UK compositional variation found in the literature. The results is a semiquantitative ranking of individual components, revealing significant differences in potential harm posed by different electronic appliances and an opportunity to provide prioritization strategies in future management.

Keywords Electronic waste $\cdot$ Hazard $\cdot$ Metals $\cdot$ Sanitary environmental risk · Toxicity

\section{Introduction}

The rapid innovation in digital technology in the last century has resulted in a dramatic increase in the production of Waste Electrical and Electronic Equipment (WEEE) (Ongondo et al. 2011; Kiddee et al. 2013). Its generation was estimated to be 41.8 million tonnes in 2014 and it is expected to increase to 65.4 million tonnes by 2017 (Breivik et al. 2014). WEEE includes several categories of end-of-life electrical appliances, so that it is a highly heterogeneous waste flow (Cucchiella et al. 2015; Golev et al. 2016). However, the main material constituent is the metallic fraction, accounting for approximately $65 \%$ of the total weight of electric and electronic equipment and including base and precious metals (Jaiswal et al. 2015). Due to the presence of valuable metals, WEEE is now regarded as urban stock, available for the mining of both precious metals and rare earth elements (REEs). The latter have received a great deal of recent attention as their supply is sensitive to many factors: REEs are provided predominantly from China and export has been limited, posing an issue of supply for conventional industrial applications (Dutta et al. 2016). The possible recovery of these strategic materials along with other valuable metals from WEEE is an important driver for the implementation of WEEE recycling practices (Binnemans et al. 2013; Tunsu et al. 2015). 
In developed countries, the recovery of materials from waste flows is also a legal obligation ( $\mathrm{Li}$ et al. 2013; Favot et al. 2016; Morris and Metternicht 2016; Zhou et al. 2017) with the procedures for the operation of recycling processes formally identified and regulated, in order to reduce environmental impact. Conversely, in developing countries, informal recycling methods are very diverse (Ardi and Leisten 2016; Salhofer et al. 2016): mechanical processes, open burning, and chemical leaching are applied under uncontrolled conditions, with the aim of liberating the components of interest from the discharged electronic appliances. However toxic substances are also released into the environment and, due to the absence of emission control systems, they can pose severe risks to both human and environmental health (Tsydenova and Bengtsson 2011; Long et al. 2013; Cao et al. 2016).

WEEE can contain a range of hazardous substances, which include potentially toxic elements (e.g., mercury, cadmium, lead) and flame retardants (e.g., pentabromophenol, polybrominated diphenyl ethers (PBDEs), tetrabromobisphenol A (TBBPA)) (Tsydenova and Bengtsson 2011).

Once released into the environment, hazardous substances can negatively affect human health through different exposure routes (Leung et al. 2008; Sepúlveda et al. 2010; Tang et al. 2010; Wei and Liu 2012; Song and Li 2015; Zeng et al. 2016), particularly the workforce or the population living in the neighborhood of informal recovery sites (Chan and Wong 2013; Sepúlveda et al. 2010). Workers suffer negative health effects by exposure through skin contact and inhalation, while the wider community is exposed to the contaminants through smoke, dust, drinking water, and food contamination (Robinson 2009).

Risk assessment is the evaluation of the potential adverse health effects on humans exposed to environmental hazards. It is carried out through the following steps (Zhang et al. 2010): (i) the identification of the potential hazards associated to the presence of selected contaminants into the environment; (ii) assessment of the exposure conditions (i.e., intensity, frequency, and duration of the exposure); (iii) assessment of the contaminant toxicity; and (iv) characterization of the risk, as the probability that the identified contamination phenomena can produce the loss of human life. Under the framework of risk assessment in informal WEEE recycling, the detailed process applied play a key role (Grant et al. 2013), influencing the mobility of hazardous substances and the extent of the environmental contamination. Shredding practices produce mainly dust that can contain both flame retardants (Morf et al. 2005) and heavy metals (Song et al. 2015). Open burning generates smokes with a variety of organic pollutants and heavy metals (Awasthi et al. 2016), whose presence is tightly related to the operating thermal conditions: reductive atmosphere promotes the evaporation of heavy metals like cadmium and zinc at lower temperatures (Dong et al. 2015; Yu et al. 2016). Moreover, the uncontrolled combustion of plastics containing brominated flame retardants has been largely reported to promote the formation of polybrominated dibenzop-dioxins/dibenzofurans (Tue et al. 2016).

Regardless of the specific informal treatment process (i.e., shredding, open burning), it is reasonable to assume that the relative risk for the exposed community, either workers or population, will be strongly related to the type of device being processed, and the variation in composition in terms of hazardous substance content. It indeed determines the presence and amount of hazardous substances available for potential release to the environment.

Toxic metals have been recognized as substances of particular concern (Tsydenova and Bengtsson 2011) and they are concentrated in specific WEEE components, such as printed circuits boards (PCBs), which are present in a wide variety of electric and electronic appliances (Oguchi et al. 2011). The hazard from different types of WEEE is mainly related to the total mass of metals contained in the PCB of each appliance as well as to the intrinsic toxicity of the metal itself.

Although the issue of the risks posed by the informal recycling of WEEE has been debated in the literature (Zhang et al. 2010; Tsydenova and Bengtsson 2011), the potential harm to human health from discharged electric and electronic devices has yet to be quantified. This work proposes and evaluates a methodology to categorize different WEEE by their relative potential for harm, assessed by reference to the metal content of their PCBs. In order to identify the most suitable parameter to express the metal toxicity, data on the possible routes for the release of these metals into the environment are discussed with reference to the more commonly reported informal recycling practice.

\section{Methodology}

The approach was to investigate and evaluate a strategy to test the significance of the metal content to define the harmful potentiality of different types of WEEE during informal recycling practices.

This was based on the metal composition of different endof-life appliances, derived from previously published assessments. As highlighted above, data focus on the metal content of printed circuit boards (PCBs) where the majority of metals are present and are widely used in electric and electronic appliances (Oguchi et al. 2011). Also, the extensive compositional analysis of the metal content of PCBs ensures that there is an opportunity to consider a wide range of potentially harmful elements and the comparative assessment of WEEE constituents are more representative of likely exposure/risk during informal recycling.

It is worth pointing out that substances of concern other than metals (i.e., flame retardants) could not be considered 
due to the lack of data on their content in different electric and electronic appliances.

\section{The composition of PCBs in terms of metal content}

The material composition of PCBs is a complex and much debated subject with high economic potential on the one side and the presence of hazardous components on the other. PCBs differ in size, function, and material composition and they should be perceived as a method for construction of an electronic circuit, rather than a distinctive electronic component.

Even though the literature presents numerous studies of the material composition of PCBs, their relevance and comparability is limited. The reasons for this are:

- insufficient information on the type of PCB that is analyzed as well as the year of production of the electronic device it belongs to: PCBs from personal computers vary in size and material composition, such as motherboard, RAM, or power supply PCBs;

- many of the PCB metals are in the milligram per kilogram range and the results of the chemical analyses are highly dependent on the method applied to assess their concentration;

- material composition data often represents composite results of repeated experiments with statistical significance or methods missing.

Consequently, the data used in our study were selected on the basis of both the background information on the PCBs analyzed and the extent of electronic categories investigated, as given in Table 1.

\section{Informal recycling methods for PCBs and exposure routes}

Both direct and indirect exposure pathways to the substances released from informal WEEE recycling have been studied (Frazzoli et al. 2010; Heacock et al. 2015). They are often related to specific informal recycling practices (Huo et al. 2007; Asante et al. 2012), which are recognized to be differently applied in diverse world regions. Large organized informal communities are present in China and India, while in Africa those activities are carried out by individuals (Schluep et al. 2009).

In China, the most dominant areas for informal treatment activities are Guiyu, in Guandong Province, and Taizhou, in Zhejiang, where the processing of PCBs focuses on the recovery of metals, especially gold, while the nonmetallic materials are landfilled (Brigden et al. 2005; Guanghan et al. 2016). The components with the highest gold content, namely silicon chips and contacts, are thus removed from PCBs and treated by leaching with acids, such as nitric and hydrochloric acids (Wang et al. 2013), for gold recovery (Wen et al. 2006;
Schluep et al. 2009). The rest of the circuit boards often goes to an acid recovery of the remaining metals (Schluep et al. 2009), but open burning has been reported as another method to treat the rest of the PCBs (Wang et al. 2013). The Chinese informal sector appears thus to rely on a number of different recycling methods: physical dismantling, heat-assisted removing of components from PCBs, chipping plastics, and melting as well as open burning for either recovery or disposal purposes are highlighted in particular (Chi et al. 2011).

A similar variety of informal recycling practices has been observed in India, where WEEE recycling takes place through traders, dismantlers, and recyclers. In Bangalore, identified as the country's information technology hub (Liu et al. 2016), the preprocessing of broken equipment includes dismantling and sorting of the waste stream into several groups: CRT, plastics, PCBs, wires and cables, and metals (Keller 2006). PCBs are dismantled into boards without electronic components, connectors, and copper. To de-solder PCBs and to recover gold, different techniques are applied. Solders are melted by using heat from an open-frame kerosene burner (Brigden et al. 2005) or coal-fire grills. Silicon chips are removed from circuit boards by putting them in a heated pool of molten lead-tin solder, and later, processed for gold extraction by using acid baths (Keller 2006; Rochat et al. 2007; Schluep et al. 2009). The rest of the boards are burned at large-scale burning facilities or leached in acid to partially recover remaining metals (Schluep et al. 2009). The residual, non-valuable fractions from those steps normally end up in open dump sites.

Different information is available for activities in Africa, where the most prominent country for informal e-waste processing is Ghana. The absence of legislation clearly banning the import of both WEEE and UEEE (Used Electric and Electronic Equipment) (Li et al. 2013), makes indeed Ghana as an eligible destination country for the illegal import of WEEE that, in turn, feeds the informal recycling sector.

In Ghana the most common practices are the manual dismantling to salvage copper and other metal-rich parts for resale (Huang et al. 2014). Dismantled components, cables, and wires are burned to extract copper (Amoyaw-Osei 2011; Huang et al. 2014). The unusable fractions from dismantling, such as plastics, are accumulated and regularly burned to reduce volume or dumped without further treatment (AmoyawOsei 2011). Chemical leaching processes for precious metal recovery from PCBs have not been observed in African countries (Schluep et al. 2009). In the case of Ghana, PCBs are ground into fine powder and exported to Asian countries, mainly China and India (Grant and Oteng-Ababio 2012).

The evidence of the adverse impacts on the environment and human health from these crude methods have been largely discussed in the literature. Several studies (Brigden et al. 2005; Leung et al. 2008; Sepúlveda et al. 2010; Tang et al. 2010; Amoyaw-Osei 2011; Wei and Liu 2012) have identified the high concentration of both metals (such as lead, nickel, 


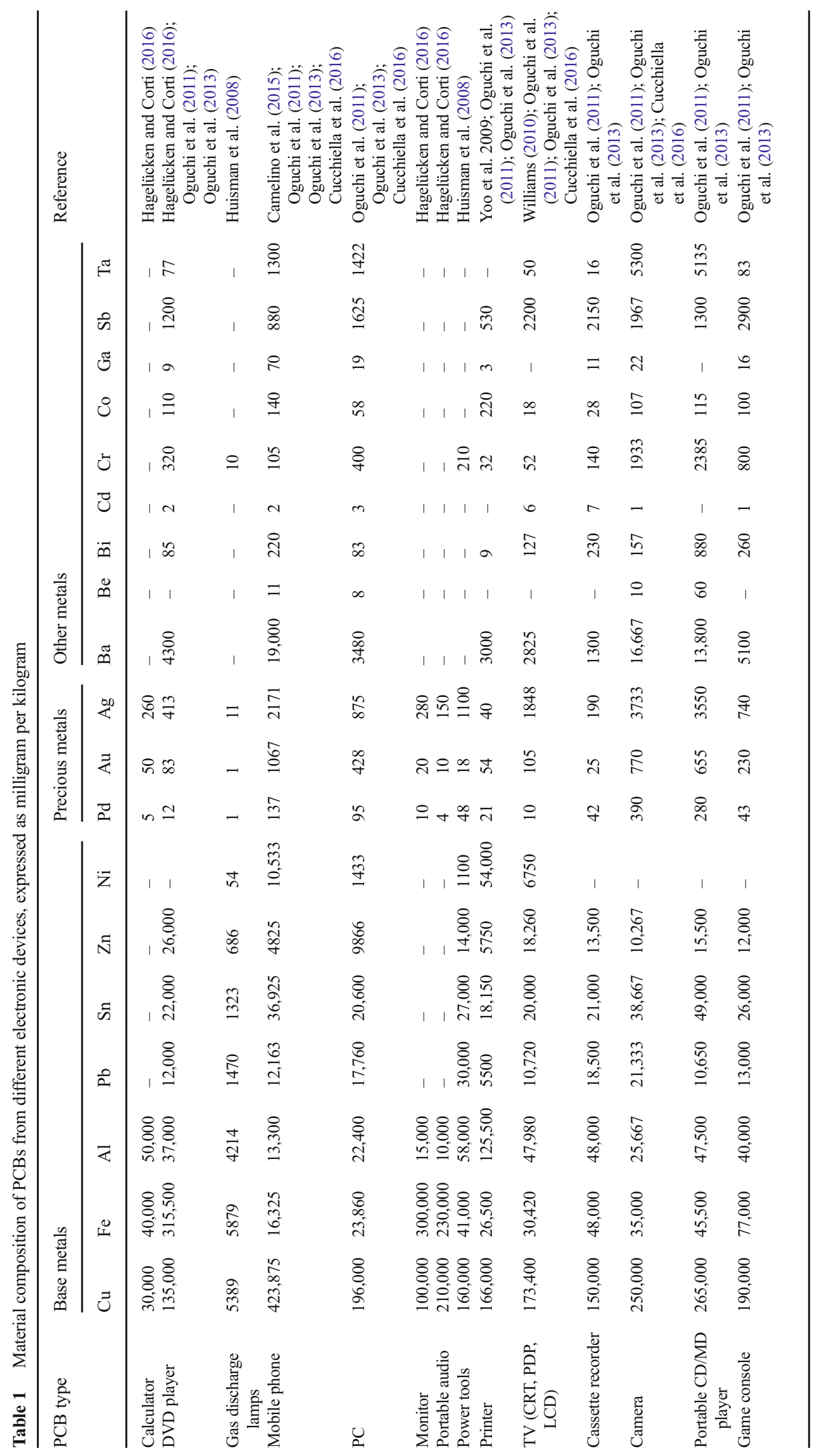


copper, cadmium), and organic pollutants in dust, sediment, and wastewater from recycling workshops or in soil and water from open pools close to recycling facilities in different regions worldwide.

Although not a comprehensive study, the practices reported to be applied in these areas could be considered as representative of the informal recycling activities, which include manual dismantling, size reduction, open burning, and acid leaching (Sepúlveda et al. 2010). Each of these uncontrolled processes affects the environmental quality through different routes (Tsydenova and Bengtsson 2011) and, in turn, human health. However, persistently poor ventilation of dusty working areas, poor hygiene, the absence of or improper use of both personal protective equipment (such as respirators), and emission control systems increase the likelihood of significant exposures mainly through inhalation, and aggravate the risk from lung related diseases (Rim et al. 2013).

\section{Approach to the assessment of the potential for harm to human health from PCBs}

Risk analysis is a useful tool to quantify the probability that the application of particular informal practice can lead to the loss of human life, providing technical data to describe the hazard that the practice itself may entail. However, the relative characterization of the risk from different informal practices seems to be limited by the lack of data on the contaminants emitted, so that it is not possible to identify the most hazardous activity. As these practices are carried out under uncontrolled operating conditions, it is indeed hard to define the chemical form and the physical state of the released contaminant, as discussed for different heavy metals in the study of Dinis and Fíuza (2011).

It is worth noting that the variability in WEEE composition can also influence the extent of the risk, as the release of hazardous substances into the environment depends on their presence and availability in different devices. In turn, the potential harm to human health from hazardous substances is related to their toxicological characteristics.

Due to the severe uncertainties in figuring out the exposure scenario for relative risk assessment, this work aims at proposing and evaluating a methodology to classify different types of WEEE by their relative potential hazard, which is estimated taking into account both the concentration and the toxicological properties of hazardous substances, namely metals, in their PCBs.

Published data on the categorization of different types of WEEE have previously been based on both the concentration and the total amount of toxic metals in their PCBs. Oguchi et al. (2013) points out that mobile phones and other small digital items such as portable audio players and digital cameras have high to moderate concentrations as well as moderate total mass of toxic metals, like chromium, barium, and lead in comparison to bigger appliances. For this reason, they were recognized as high priority items, when managing toxic metals in WEEE. On the other hand, the total amounts of toxic metals contained in other midsized items such as audio/video devices and ICT equipment, including printers, were not negligible, but their concentration was not particularly high (Oguchi et al. 2013). However, this assessment focused only on the quantity of a few selected metals.

For the present work, standardized database from environmental risk assessment was used (US-EPA 2016).

The impact of environmental exposure determines the risk assessment of potentially toxic elements. Based on the study of informal recycling methods, the toxicity inhalation path was considered as the most relevant and the corresponding toxicity value, namely the inhalation reference concentration (RfC), was selected for each metal (Table 2). The RfC is an estimate of a concentration under continuous exposure for individuals that does not present any risk of deleterious effects during a lifetime. Selected RfC values referred to the elemental metal or, if not available, to a metal compound that is likely to be produced during informal recycling practices, such as open burning.

For the identified PCBs, the contribution to the potential for harm indicator of the $\mathrm{i}$-th metal $\left(\mathrm{PHI}_{\mathrm{i}}\right)$ was calculated as the ratio between its concentration in the PCB and the correspondent RfC. The total indicator of the potential for harm (PHI), based on the presence of the " $n$ " contaminants, was then assessed through the following expression:

$P H I=\sum_{\mathrm{i}=1}^{\mathrm{n}} \mathrm{PHI}_{\mathrm{i}}$

A schematic of the construction of the indicator is shown in Figure 1.

The comparative analysis of the PHI of PCB was also referred to a normalized PHI (DPHI), which was calculated as the ratio between the PHI of the single PCB and the minor PHI.
Table 2 Reference concentrations selected as toxicity values (USEPA)

\begin{tabular}{ll}
\hline Metal & $\mathrm{RfC}\left[\mu \mathrm{g} / \mathrm{m}^{3}\right]$ \\
\hline Aluminum (Al) & 5 \\
Barium (Ba) & 0.5 \\
Beryllium (Be) & 0.02 \\
Cadmium (Cd) & 0.01 \\
Chromium (Cr) & 0.1 \\
Cobalt (Co) & 0.006 \\
Lead (Pb) & 0.2 \\
Nickel (Ni) & 0.014 \\
Strontium (Sr) & 0.2 \\
\hline
\end{tabular}


Fig. 1 Flow chart of the developed methodology

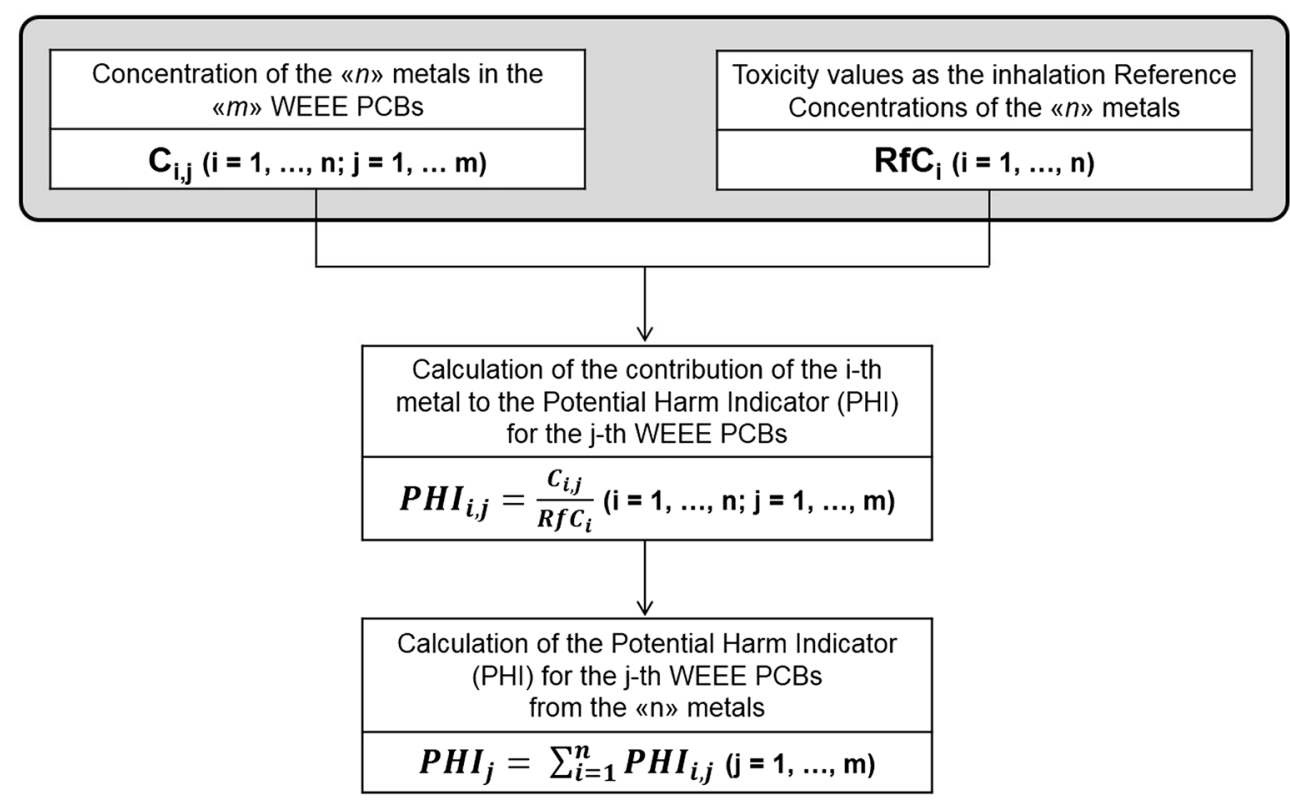

\section{Results and discussion}

The methodology provides a simple potential for harm indicator (PHI), expressed as an inverse reference concentration referred to the mass of the PCB rather than the metal. This indicator highlights the significance of specific WEEE components relative to each other. The higher the value of PHI, the more significant hazard a particular WEEE component may be for human health. The weight of individual appliances does not play any role in the definition of the PHI, as the results are normalized per mass unit of the device to allow a suitable comparison between different sizes of WEEE. The relevance of this work is in its use to supply a means of classification of components, which may provide a role in prioritization of decision making in management of waste streams, as highlighted in Table 3.

According to these results, the significance of the PCBs from particular WEEE types is:

printer $>$ mobile phone $>\mathrm{TV}>$ power tools $>$ PC $>$ camera $>$ portable $\mathrm{CD} / \mathrm{MD}$ player $>$ cassette recorder $>$ game console $>$ DVD player $>$ gas discharge lamps $>$ calculator $>$ monitor $>$ portable audio.

Therefore, when considering the sustainable management of WEEE, printers should be considered at the highest level of priority. The PHI for printers was found to be approximately 2000 times higher than that of the portable audio, which is the lowest. According to the order of magnitude of the DPHI, the other PCB types can be clustered in the following classes:

- class 1, including mobile phone, TV, power tools, and PC, with PHI values from 445 to 109 times that for portable audio;
- class 2, consisting of camera, portable CD/MD player, cassette recorder, game console, and DVD player, whose PHI values were in the range 50-92 times higher than that of portable audio;

- class 3, composed of gas discharge lamps, calculator, monitor, and portable audio, with DPHI lower than 10.

With the exception of the game console and gas discharge lamps, belonging to the categories n. 7 (toys, leisure, and sport equipment) and n. 5 (lighting equipment) of the European WEEE Directive respectively; the considered devices are listed in either the category n. 3 (IT and telecommunications equipment) or the category n. 4 (consumer equipment) of the same Directive.

Table 3 Relative potential harm of selected WEEE

\begin{tabular}{lll}
\hline PCB type & DPHI & DPHI $_{\text {no Al }}$ \\
\hline Printer & 1.977 & 347 \\
Mobile phone & 445 & 78 \\
TV (CRT, PDP, LCD) & 278 & 48 \\
Power tools & 121 & 20 \\
PC & 109 & 19 \\
Camera & 92 & 16 \\
Portable CD/MD player & 69 & 11 \\
Cassette recorder & 56 & 9 \\
Game console & 55 & 9 \\
DVD player & 50 & 8 \\
Gas discharge lamps & 6 & 1 \\
Calculator & 5 & - \\
Monitor & 2 & - \\
Portable audio & 1 & - \\
\hline
\end{tabular}


As pointed out by (Tansel 2017), the quantities of discarded electronic consumer products have increased exponentially, due to advancing technology, manufacturing processes, rapid market penetration, and planned obsolescence. However, for a large portion of this waste, recycling is not properly documented, suggesting it is likely to be handled under uncontrolled conditions, with consequences for risks to both human and environmental health. Further efforts should be made to provide a barrier to exposure and the categorization of WEEE by their PHI indicates the order of priority that should be followed in defining the strategies for the traceability of different kinds of WEEE. This may allow the adoption of basic, easy-to-apply practices during the informal recycling of the appliances.

The methodology also highlights that the individual content of metals is not sufficient for prioritization of WEEE management.

This work highlights printers as the most significant component of WEEE, with high content in aluminum, nickel, and cobalt. The less harmful category (portable audio) has typically lower concentrations of aluminum and nickel as well as cobalt being absent.

Although such outcomes seem to suggest a linear relationship between the concentration of these metals and the PHI value, the results obtained for the other devices do not support this conclusion, as the potential danger from a specific device is related directly to the toxicity potential of its constituents. In the studied PCBs, metals like cobalt are present at low concentrations, but the corresponding reference concentration is also very low, indicating a high toxic potential. Conversely, aluminum is one of the main constituents of PCBs, but its toxicity expressed as reference concentration is three order of magnitude greater than that of cobalt.

The analysis of the ranking results, shown in Table 3, identifies that the aluminum concentration $(13,300 \mathrm{mg} / \mathrm{kg})$ of mobile phone PCB cannot be related to the corresponding PHI value, as observed for printers.

Although the concentrations of aluminum are very high, ranging between 4214 and $125,500 \mathrm{mg} / \mathrm{kg}$, the presence of this substance do not affect considerably the potential for harm of the considered PCBs: in fact, due to the low toxicity of this metal, the priority ranking based on the PHI values do not change if not considering the presence of aluminum, as shown in Table $3\left(\mathrm{DPHI}_{\mathrm{no} \mathrm{Al}}\right)$. Different consideration raise for nickel, whose presence drives the definition of the PHI values for the PCB of the WEEE types clustered in class 1. Although most of these devices contain cobalt, which is even more toxic than nickel, the latter is present in concentrations approximately 100,000-fold higher than the corresponding RfC. Similarly, for the devices grouped in class 2 , lead is the metal characterized by a concentration ranging between 12,000 and $21,300 \mathrm{mg} / \mathrm{kg}$, which is up to 100,000 -fold higher than its RfC. The contribution of other metals, like barium, cadmium, and chromium, to the overall PHI determines the order of priority of the single WEEE type PCBs within each cluster, namely class 1 , class 2 , and class 3 . This analysis suggests that, when the metal concentration is, at least, 50,000-fold higher than the RfC, its presence drives the definition of the potential harm of the corresponding PCB.

It is worth identifying that all appliances contain large amounts of copper and iron and most of them also contain other metals like zinc that do not contribute to the assessment due to the lack of comparable toxicity data. It is therefore important that data should be generated to refine the model and subsequent classification of WEEE components.

In the wider context of environmental risk assessment, the absence of inhalation route data on a number of elements limits the evaluation of the risk to individuals exposed to either dust or gaseous emissions from informal WEEE recycling practices. Although the concentration in air of some metals, including copper and iron, has been reported in working places where either dismantling or other uncontrolled recycling practices are performed (Julander et al. 2014; Zeng et al. 2015), it is still not possible to verify the effects of those concentrations to human health after a chronic exposure. Similarly, the identification of correlation between health effects and metal concentrations (Perkins et al. 2014) do not provide suitable information to address the definition of riskbased procedures.

This methodology represents a possible approach to address this gap and needs to be widened with reference to both components of WEEE and individual substance toxicity. Field studies focused on the monitoring of substances released during informal WEEE treatment would further promote the verification of exposure conditions for either recyclers or population living in the surroundings of working sites.

The prioritization of control measures in the sustainable management of WEEE needs to take into account the device as well as the PCB. Further refinement can be made by identifying metal speciation and toxicity of specific compounds likely to be encountered during the processing of the waste. In addition, other toxic substances should also be considered as their adverse effects on both environment and human health have been extensively reported (Herat and Agamuthu 2012). To this end, further efforts should be directed towards the quantification of nonmetallic substance of concern in electric and electronic appliances.

\section{Conclusions}

This work proposes a methodology to assess the relative potential for harm to human health from the informal recycling of different types of WEEE. The informal processing of WEEE, which is largely performed in developing countries, poses a severe risk for both the human health and the environment, related to the possible release of toxic substances during the 
uncontrolled treatment of waste components. Rudimentary shredding and open burning are among the most commonly reported procedures applied to recover valuable materials, and they raise great concern due to the potential for inhalation of contaminated air by either workers or people living in the surrounding of the informal working sites.

This methodology was able to provide the potential harm indicator (PHI), which takes into account both the amount and the toxicological properties of the metals of concern, primarily present in the printed circuit boards. The total quantity as well as the toxicological properties of these metals is the main factor contributing to the overall potential for harm of discharged electronic devices. The potential harm from different types of WEEE can be driven by the presence of the more toxic metals that are of a significant mass. However, when the content of these metals is lowered, the potential harm is driven by the relative content of the toxic elements.

Printers were identified as the most hazardous type of WEEE, followed by several kinds of both IT and consumer appliance, which should be regarded as high-priority devices when considering their informal treatment.

This methodology represents a useful tool for WEEE management, indicating an order of priority for the definition of both strategies and easy-to-apply practices aimed at reducing the extent of adverse effects during the informal processing of the appliances.

However, there is an urgent need for further studies, looking at a more comprehensive characterization of the hazardous substances in different types of WEEE components. Data identification and collection should be undertaken along with field studies to validate the results from the assessment. An understanding of the specific informal recycling methodology is also of interest as it will then identify most appropriate exposure models.

Acknowledgements This article is based on work from COST Action ES 1407 ReCreew-European network for innovative recovery strategies of rare earth and other critical metals from electrical and electronic waste, supported by COST (European Cooperation in Science and Technologywww.cost.eu). Authors deeply appreciated the support of Federica Scaini in the definition of the toxicological parameters.

Open Access This article is distributed under the terms of the Creative Commons Attribution 4.0 International License (http:// creativecommons.org/licenses/by/4.0/), which permits unrestricted use, distribution, and reproduction in any medium, provided you give appropriate credit to the original author(s) and the source, provide a link to the Creative Commons license, and indicate if changes were made.

\section{References}

Amoyaw-Osei Y (2011) Ghana e-Waste Country Assessment

Ardi R, Leisten R (2016) Assessing the role of informal sector in WEEE management systems: a system dynamics approach. Waste Manag 57:3-16. https://doi.org/10.1016/j.wasman.2015.11.038
Asante KA, Agusa T, Biney CA et al (2012) Multi-trace element levels and arsenic speciation in urine of e-waste recycling workers from Agbogbloshie, Accra in Ghana. Sci Total Environ 424:63-73. https://doi.org/10.1016/j.scitotenv.2012.02.072

Awasthi AK, Zeng X, Li J (2016) Environmental pollution of electronic waste recycling in India: a critical review. Environ Pollut 211:259 270. https://doi.org/10.1016/j.envpol.2015.11.027

Binnemans K, Jones PT, Blanpain B et al (2013) Recycling of rare earths: a critical review. J Clean Prod 51:1-22. https://doi.org/10.1016/j. jclepro.2012.12.037

Breivik K, Armitage JM, Wania F, Jones KC (2014) Tracking the global generation and exports of e-waste. Do existing estimates add up? Environ Sci Technol 48:8735-8743. https://doi.org/10.1021/ es5021313

Brigden K, Labunska I, Santillo D, et al (2005) Recycling of electronic wastes in China and India: workplace and environmental contamination

Camelino S, Rao J, Padilla RL, Lucci R (2015) Initial studies about gold leaching from printed circuit boards (PCBs) of waste cell phones. Procedia Mater Sci 9:105-112

Cao J, Chen Y, Shi B et al (2016) WEEE recycling in Zhejiang Province, China: generation, treatment, and public awareness. J Clean Prod 127:311-324. https://doi.org/10.1016/j.jclepro.2016.03.147

Chan JKY, Wong MH (2013) A review of environmental fate, body burdens, and human health risk assessment of PCDD/Fs at two typical electronic waste recycling sites in China. Sci Total Environ 463-464:1111-1123. https://doi.org/10.1016/j.scitotenv.2012.07. 098

Chi X, Streicher-Porte M, Wang MYL, Reuter MA (2011) Informal electronic waste recycling: a sector review with special focus on China. Waste Manag 31:731-742. https://doi.org/10.1016/j.wasman.2010. 11.006

Cucchiella F, D'Adamo I, Lenny Koh SC, Rosa P (2015) Recycling of WEEEs: an economic assessment of present and future e-waste streams. Renew Sust Energ Rev 51:263-272. https://doi.org/10. 1016/j.rser.2015.06.010

Cucchiella F, D'Adamo I, Lenny Koch SC, Rosa P (2016) A profitability assessment of European recycling processes treating printed circuit boards from waste electric and electronic equipments. Renew Sust Energ Rev 64:749-760

Dinis ML, Fíuza A (2011) Exposure assessment to heavy metals in the environment: measures to eliminate or reduce the exposure to critical receptors. In: Simeonov LI et al (eds) Environmental Heavy Metal Pollution and Effects on Child Mental Development: Risk Assessment and Prevention Strategies. doi:https://doi.org/10.1007/ 978-94-007-0253-0_2

Dong J, Chi Y, Tang Y et al (2015) Partitioning of heavy metals in municipal solid waste pyrolysis, gasification, and incineration. Energy Fuel 29:7516-7525. https://doi.org/10.1021/acs.energyfuels. 5 b01918

Dutta T, Kim K-H, Uchimiya M et al (2016) Global demand for rare earth resources and strategies for green mining. Environ Res 150:182190. https://doi.org/10.1016/j.envres.2016.05.052

Favot M, Veit R, Massarutto A (2016) The evolution of the Italian EPR system for the management of household waste electrical and electronic equipment (WEEE). Technical and economic performance in the spotlight. Waste Manag 56:431-437. https://doi.org/10.1016/j. wasman.2016.06.005

Frazzoli C, Orisakwe OE, Dragone R, Mantovani A (2010) Diagnostic health risk assessment of electronic waste on the general population in developing countries' scenarios. Environ Impact Assess Rev 30: 388-399. https://doi.org/10.1016/j.eiar.2009.12.004

Golev A, Schmeda-Lopez DR, Smart SK et al (2016) Where next on ewaste in Australia? Waste Manag 58:348-358. https://doi.org/10. 1016/j.wasman.2016.09.025 
Grant R, Oteng-Ababio M (2012) Mapping the invisible and real "African" economy: urban e-waste circuitry. Urban Geogr 33:121. https://doi.org/10.2747/0272-3638.33.1.1

Grant K, Goldizen FC, Sly PD et al (2013) Health consequences of exposure to e-waste: a systematic review. Lancet Glob Health 1: e350-e361

Guanghan S, Zhu X, Wenyi Y et al (2016) Recycling and disposal technology for non-mentallic materials from waste printed circuit boards(WPCBs) in China. Procedia Environ Sci 31:935-940. https://doi.org/10.1016/j.proenv.2016.02.114

Hagelücken C, Corti C (2016) Recycling of gold from electronics: costeffective use through "Design for Recycling". Gold Bull 43(3):209

Heacock M, Kelly CB, Asante KA et al (2015) E-waste and harm to vulnerable Populations: a growing global problem. Environ Health Perspect. https://doi.org/10.1289/ehp.1509699

Herat S, Agamuthu P (2012) E-waste: a problem or an opportunity? Review of issues, challenges and solutions in Asian countries. Waste Manag Res J Int Solid Wastes Public Clean Assoc ISWA 30:1113-1129. https://doi.org/10.1177/0734242X12453378

Huang J, Nkrumah PN, Anim DO, Mensah E (2014) E-waste disposal effects on the aquatic environment: Accra, Ghana. Rev Environ Contam Toxicol 229:19-34. https://doi.org/10.1007/978-3-31903777-6 2

Huisman J et al. (2008) Review of directive 2002/96 on waste electrical and electronic equipment (WEEE), final report. United Nations University

Huo X, Peng L, Xu X et al (2007) Elevated blood lead levels of children in Guiyu, an electronic waste recycling town in China. Environ Health Perspect 115:1113-1117. https://doi.org/10.1289/ehp.9697

Jaiswal A, Samuel C, Patel BS, Kumar M (2015) Go green with WEEE: eco-friendly approach for handling e-waste. Procedia Comput Sci 46:1317-1324. https://doi.org/10.1016/j.procs.2015.01.059

Julander A, Lundgren L, Skare L et al (2014) Formal recycling of e-waste leads to increased exposure to toxic metals: an occupational exposure study from Sweden. Environ Int 73:243-251. https://doi.org/ 10.1016/j.envint.2014.07.006

Keller, M (2006) Assessment of gold recovery processes in Banaglore, India and evaluation of an alternative recycling path for printed wiring boards. Institute for Spatial and Landscape Planning, Regional resource management ; Empa, Technology and Society $\mathrm{Lab}$

Kiddee P, Naidu R, Wong MH (2013) Electronic waste management approaches: an overview. Waste Manag 33:1237-1250. https://doi. org/10.1016/j.wasman.2013.01.006

Leung AOW, Duzgoren-Aydin NS, Cheung KC, Wong MH (2008) Heavy metals concentrations of surface dust from e-waste recycling and its human health implications in Southeast China. Environ Sci Technol 42:2674-2680. https://doi.org/10.1021/es071873x

Li J, Lopez NBN, Liu L et al (2013) Regional or global WEEE recycling. Where to go? Waste Manag 33:923-934. https://doi.org/10.1016/j. wasman.2012.11.011

Liu H, Lei M, Deng H et al (2016) A dual channel, quality-based price competition model for the WEEE recycling market with government subsidy. Omega 59(Part B):290-302. https://doi.org/10.1016/j. omega.2015.07.002

Long Y-Y, Feng Y-J, Cai S-S et al (2013) Flow analysis of heavy metals in a pilot-scale incinerator for residues from waste electrical and electronic equipment dismantling. J Hazard Mater 261:427-434. https:// doi.org/10.1016/j.jhazmat.2013.07.070

Morf LS, Tremp J, Gloor R et al (2005) Brominated flame retardants in waste electrical and electronic equipment: substance flows in a recycling plant. Environ Sci Technol 39:8691-8699. https://doi. org/10.1021/es051170k

Morris A, Metternicht G (2016) Assessing effectiveness of WEEE management policy in Australia. J Environ Manag 181:218-230. https:// doi.org/10.1016/j.jenvman.2016.06.013
Oguchi M, Murakami S, Sakanakura H et al (2011) A preliminary categorization of end-of-life electrical and electronic equipment as secondary metal resources. Waste Manag 31:2150-2160. https://doi. org/10.1016/j.wasman.2011.05.009

Oguchi M, Sakanakura H, Terazono A (2013) Toxic metals in WEEE: characterization and substance flow analysis in waste treatment processes. Sci Total Environ 463-464:1124-1132. https://doi.org/10. 1016/j.scitotenv.2012.07.078

Ongondo FO, Williams ID, Cherrett TJ (2011) How are WEEE doing? A global review of the management of electrical and electronic wastes. Waste Manag 31:714-730. https://doi.org/10.1016/j.wasman.2010. 10.023

Perkins DN, Brune Drisse M-N, Nxele T, Sly PD (2014) E-waste: a global hazard. Ann Glob Health 80:286-295. https://doi.org/10. 1016/j.aogh.2014.10.001

Rim KT, Koo KH, Park JS (2013) Toxicological evaluations of rare earths and their health impacts to workers: a literature review. Saf Health Work 4:12-26. https://doi.org/10.5491/SHAW.2013.4.1.12

Robinson BH (2009) E-waste: an assessment of global production and environmental impacts. Sci Total Environ 408:183-191. https://doi. org/10.1016/j.scitotenv.2009.09.044

Rochat D, Hagelüken C, Keller M, Widmer R (2007) Optimal recycling for printed wiring boards (PWBs) in India

Salhofer S, Steuer B, Ramusch R, Beigl P (2016) WEEE management in Europe and China-a comparison. Waste Manag 57:27-35. https:// doi.org/10.1016/j.wasman.2015.11.014

Schluep M, Hagelüken C, Kuehr R, et al (2009) Recycling. From e-waste to resources. Recycl.E-Waste Resour

Sepúlveda A, Schluep M, Renaud FG et al (2010) A review of the environmental fate and effects of hazardous substances released from electrical and electronic equipments during recycling: examples from China and India. Environ Impact Assess Rev 30:28-41. https://doi.org/10.1016/j.eiar.2009.04.001

Song Q, Li J (2015) A review on human health consequences of metals exposure to e-waste in China. Environ Pollut 196:450-461. https:// doi.org/10.1016/j.envpol.2014.11.004

Song Q, Zeng X, Li J et al (2015) Environmental risk assessment of CRT and PCB workshops in a mobile e-waste recycling plant. Environ Sci Pollut Res 22:12366-12373. https://doi.org/10.1007/s11356015-4350-9

Tang X, Shen C, Shi D et al (2010) Heavy metal and persistent organic compound contamination in soil from Wenling: an emerging ewaste recycling city in Taizhou area, China. J Hazard Mater 173: 653-660. https://doi.org/10.1016/j.jhazmat.2009.08.134

Tansel B (2017) From electronic consumer products to e-wastes: global outlook, waste quantities, recycling challenges. Environ Int 98:3545. https://doi.org/10.1016/j.envint.2016.10.002

Tsydenova O, Bengtsson M (2011) Chemical hazards associated with treatment of waste electrical and electronic equipment. Waste Manag 31:45-58. https://doi.org/10.1016/j.wasman.2010.08.014

Tue NM, Goto A, Takahashi S et al (2016) Release of chlorinated, brominated and mixed halogenated dioxin-related compounds to soils from open burning of e-waste in Agbogbloshie (Accra, Ghana). J Hazard Mater 302:151-157. https://doi.org/10.1016/j.jhazmat.2015. 09.062

Tunsu C, Petranikova M, Gergorić M et al (2015) Reclaiming rare earth elements from end-of-life products: a review of the perspectives for urban mining using hydrometallurgical unit operations. Hydrometallurgy 156:239-258. https://doi.org/10.1016/j.hydromet. 2015.06.007

US-EPA (2016) Regional screening levels-generic Tables (May 2016). https://www.epa.gov/risk/regional-screening-levels-rsls-generictables-may-2016

Wang F, Kuehr R, Ahlquist D, Li J (2013) E-waste in China-a country report 
Wei L, Liu Y (2012) Present status of e-waste disposal and recycling in China. Procedia Environ Sci 16:506-514. https://doi.org/10.1016/j. proenv.2012.10.070

Wen X, Li J, Hao L, et al (2006) An agenda to move forward r-waste recycling and challenges in China. In: Proceedings of the 2006 I.E. International Symposium on Electronics and the Environment, 2006. pp 315-320

Williams PT (2010) Valorization of printed circuit boards from waste electrical and electronic equipment by pyrolysis. Waste Biomass Valorization 1:107-120

Yoo JM, Jeong J, Yoo K, Lee Jc, Kim W (2009) Enrichment of the metallic components from waste printed circuit boards by a mechanical separation process using a stamp mill. Waste Manage 29(3): $1132-1137$

Yu J, Sun L, Wang B et al (2016) Study on the behavior of heavy metals during thermal treatment of municipal solid waste (MSW) components. Environ Sci Pollut Res 23:253-265. https://doi.org/ 10.1007/s11356-015-5644-7

Zeng X, Song Q, Li J et al (2015) Solving e-waste problem using an integrated mobile recycling plant. J Clean Prod 90:55-59. https:// doi.org/10.1016/j.jclepro.2014.10.026

Zeng X, Xu X, Boezen HM, Huo X (2016) Children with health impairments by heavy metals in an e-waste recycling area. Chemosphere 148:408-415. https://doi.org/10.1016/j.chemosphere.2015.10.078

Zhang K, Pei Y, Lin C (2010) An investigation of correlations between different environmental assessments and risk assessment. Procedia Environ Sci 2:643-649. https://doi.org/10.1016/j.proenv.2010.10. 072

Zhou W, Zheng Y, Huang W (2017) Competitive advantage of qualified WEEE recyclers through EPR legislation. Eur J Oper Res 257:641655. https://doi.org/10.1016/j.ejor.2016.07.050 